\title{
Developmental Changes and Behavior Problems in Children: A Brief Review
}

\author{
Yogesh Kumar ${ }^{1}$, Jogindravati ${ }^{2}$ \\ ${ }^{1}$ Scholar for Ph.D (Nursing), Mahatma Jyoti Rao Phoole University, Jaipur (Rajasthan). \\ ${ }^{2}$ Professor and Principal, Sri Guru Harikrishan Sahib College of Nursing, Sohana, Mohali (Punjab)
}

\begin{abstract}
The importance of early identification of child with a health problem and prompt and adequate treatment is well known to medical practice, nursing care and public health. Failing to diagnose early and treat promptly may often cause severe morbidity and serious lasting complications in later life. Children are immature and developing individuals whose capacities and coping skills change markedly during childhood. Developmental changes in children occur rapidly between 2 to 5 years. Children at this age often engage in aggressive and rebellious behaviors. Behavior problems in children are an important social, educational, and health issue. The prevalence of these problems, their stability over time, their poor prognosis, and their costs to both individuals and the society, all point to the need for primary prevention and early effective interventions. Early identification of and early intervention for children with behavioral problems can help parents better care for their child and the child's siblings, as well as support them in the challenges they face in their community.
\end{abstract}

Keywords: Behavior problems, Children, Behavioral variables, Behavioral interventions, Developmental changes in children

\section{Introduction}

Behavior problems are the disorders that represent significant deviation from the normal behavior. These disorder are relatively stable, internalized and difficult to treat than the adjustment reaction but less so than neurosis and psychosis. The hyperkinetic reaction, runway reaction and group delinquency are examples of behavioral disorder. The root of the problem usually is traceable to the home and /or the school environment. When children fail to control their behavior and are unable to verbalize their problems, they may resort to frequent aggressive behavior as an outward manifestation of their emotions. When the parents report a solitary symptom in the absence of any other major illness in the child, it is classified as special symptoms. Common examples of this category are nail biting, thumb sucking, and enuresis.

Developmental changes in children occur rapidly between 2 to 5 years due to that it can be a difficult time for most parents. Children at this age often engage in aggressive and rebellious behaviors. For most children, some aggressive or rebellious behaviors are a normal developmental milestone. Usually, these behaviors pass quickly as the children learn to control their behaviors and develop alternative methods of accomplishing their objectives. Most children gradually become more cooperative between 3 and 5 years old. They can think and remember better. They learn more about using and listening to words. They get better at controlling their emotions and their behavior. Moreover, they learn what adults expect of them. ${ }^{(1)}$

Symptoms arise in times of stress (birth of sibling, starting school, life-threatening illness) when the demands on the child are excessive. The child may cope successfully with the stress, thereby enhancing self-esteem and confidence. Alternatively the child may be overwhelmed, responding with the development of symptomatic behavior. ${ }^{(2)}$
Behavior problems are the disorders that represent significant deviation from the normal behavior. Early childhood regulatory disorders account for the most common behavioral abnormalities of the infant and young child that result from regulatory problems associated with age specific adaptation and developmental tasks. Increasing empirical evidence indicates that these problems need to receive full attention. If left to themselves, such disorders impair the early parent-child relationship, and increase the risk of disturbances later on in life. ${ }^{(3)}$

Behavioral variables are response to toys, attention span, cooperativeness, reactivity, happiness, endurance, temper tantrums, fears, discipline problems, general fussiness, ability to play alone, getting along with playmates, mild and severe accidents, school achievement, destructiveness, attention-seeking, stubbornness, shouting, jealousy, and cleaning up toys. $^{(4)}$

Behavior problems in children are common, and they most commonly result from the child's need for autonomy and exploration behavior problems, children, hitting, biting, temper tantrums, aggression, bed-wetting, thumb-sucking, biting and hitting, sleep problems, specific eating problems etc. These needs arise from the child's newly acquired mobility and communication skills. ${ }^{(5)}$

In the studies conducted over the last fifty years, prevalence rate of behavior problems varied from $5 \%-51 \%$. In the Indian studies prevalence rate varied from 13 per thousand to 431 per thousand. Analysis at pediatric out patients department revealed behavior problems in the range of $3.36 \%$ to $50 \%$. Single parenting and violence have been associated with increased behavioral problems in children. ${ }^{(6)}$ Behavioral interventions and parental training have shown promise in decreasing problematic behaviors in preschoolage children. Healthy Steps was a clinical trial (including 5565 children enrolled at birth and with a 5.5-year followup) that integrated developmental specialists and improved developmental services into pediatric care in the first three

\section{Volume 4 Issue 12, December 2015}




\section{International Journal of Science and Research (IJSR) \\ ISSN (Online): 2319-7064}

Index Copernicus Value (2013): 6.14 | Impact Factor (2014): 5.611

years of life. The results indicated that a comprehensive program that is provider-based could contribute to a child's healthy development and reduce behavioral problems. ${ }^{(7)}$

Behavior: is the action or reaction of something under specified circumstances.

\section{Behavioral Problem:}

Include disorder that represents significant deviation from the normal behavior.

Any behavior that disturbs the individual's ability to function adequately will constitute a behavior problem.

These disorder are relatively stable, internalized and difficult to treat than the adjustment reaction but less so than neurosis and psychosis.

The hyperkinetic reaction, runway reaction and group delinquency are examples of behavioral disorder.

When the parents report a solitary symptom in the absence of any other major illness in the child, it is classified as special symptoms.

Common examples of this category are nail biting, thumb sucking, and enuresis.

\section{Factor associated with behavioral problems:}

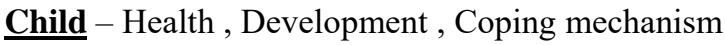

Parents- Misinterpreted behavior, Mismatched expectations, Parenting style, Coping mechanism

\section{Environment- Stress, Support}

Types of behavioral problems in relation to age group:

a) Infancy

- Feeding problem

- Colic

- Stranger anxiety

- Breath holding spells

- Temper tantrum

- Thumb sucking

b) Mid-Childhood

- Stuttering

- Pica

- Sleep problem

- Enuresis

- Encopresis

c) Preschool Child

- Hyperactive or restless child

- Head banging/Body rocking

- Thumb sucking

- Nail biting

- Masturbation

- Lack of clarity in speech

- Stealing

- Telling lie

- Sleep disorder

- Shyness

\section{d) Feeding Problems}

- Underfeeding

- Overfeeding

A survey was conducted among the school children to determine emotional and behavioral problems among school going children of 5 to 11 years of age. 675 parents of 8 communities and 7 private schools participated in the study. Assessment of children mental health was conducted using Strengths and Difficulties Questionnaire (SDQ). Parents rated $34.4 \%$ of children and teacher stated $35.8 \%$ of children as falling under the abnormal category on SDQ. A gender difference was identified related to prevalence; boys had higher estimates of behavior/externalizing problems, whereas emotional problems were more common among females. ${ }^{(8)}$

About prevalence a study was conducted in February 2014 in Ahmedabad, Gujarat, India. The aim of study was to find out the prevalence and underlying its risk factors of nocturnal enuresis in age groups 5 to 12 years in the rural areas of the district on total 1258 school children including 869 males and 389 females residing in rural areas of Ahmadabad district of Gujarat state by the help of health personnel staff with the cooperation of the teaching staff and all the parents of the children. Study found the prevalence of nocturnal enuresis in $11.13 \%$ of total subjects. Nocturnal enuresis was more common in males than in females, 91/140 in males and 49/140 in female children. Findings suggest that nocturnal enuresis is a common problem among school children especially with low income, lower age, family history of enuresis and history of urinary tract infection. Enuresis is a pediatric public health problem and efforts at all levels should be made such as preventive, etiological and curative. The ratio of males to females in this study was 1.86 that is comparable to other data of the same study. ${ }^{(9)}$

Knowledge regarding behavior problems with the Child Behavior Checklist was carried out. The analysis revealed that $40 \%$ children were above cutoff score. Mean child behavior check list (CBCL) score was 40. Total of $72 \%$ children were from armed forces background of which $9 \%$ were siblings of officers. $30.6 \%$ children from the armed forces background were above the cutoff score. There was no significant difference in the behavior problems between different age groups and sex and behavior problems between children of officers, other ranks or various income groups. Female children had behavior problems like being too concerned with neatness or cleanliness, need to be perfect and argue a lot where as male children had behavior problems not feel guilty after misbehavior, argues a lot and being restless. ${ }^{(10,11)}$

A case control study was conducted to assess the prevalence of behavior disorders in school going children and to compare the socio-demographic variables and other related factors with behavior disorders. Result showed that prevalence of behavior disorders was found to be $10.25 \%$ with higher in males than females. The study concluded that there is need for some community based programme to raise the level of awareness and knowledge about these disorders in general population. ${ }^{(\mathbf{1 2})}$ 


\section{International Journal of Science and Research (IJSR) \\ ISSN (Online): 2319-7064}

Index Copernicus Value (2013): 6.14 | Impact Factor (2014): 5.611

A study was done to compare the level of behavioral problems among preschool children of 100 employed and unemployed mothers in Bangalore. The result showed that 50 preschool children of employed mothers $33(66 \%)$ of them had moderate behavioral problems (17\%); 34 of them had mild behavioral problems and none of them had severe behavioral problems. The study concluded that there is a significant association between the levels of behavioral problems with age of the child, religion, grade of the child, religion among preschool children of employed mother with their selected demographic variables. ${ }^{(13)}$

Another study was done on effect of television watching on aggressive behavior of toddler shows that, children who watched too much television become aggressive and suffered from poor attention span. It also found that the number of children who were spending more time in front of television is also raised. ${ }^{(\mathbf{1 4})}$

\section{References}

[1] Hockberry, Wilson, winkelsteina, kelin, Wong's. Nursing Care of New born and Children: health promotion of children, Philadelphia: Elsevier, 2005. $601,05,07, \& 09 a$

[2] Mukherjee $\mathrm{B} \quad \mathrm{S}$ D. Available From : http://www.pediatriconcall.com/fordoctor/Conference_a bstracts/report.aspx?reportid

[3] Papousek M. Regulatory disorders in early childhood: Family physician counseling for crying, sleeping and feeding disorders. MMW Fortschr Med.2005 Mar; 147(12): 32-4.

[4] http://www.childtrends.org/?programs=child-health supervision\#sthash.afzw4LAj.dpuf

[5] Dorothy R Marlow, Barbara A Redding. Text book of pediatric nursing; behavioral characteristics of children. Philadelphia: Elsevier, 2005.733-34

[6] Park K, Park JF. Park's Text book of Preventive Social Medicine. 17th ed. New Delhi: BanarsidasBhanot Publishers; 2002.p.137-45.

[7] Mukherjee B S D. Available From : http://www.pediatriconcall.com/fordoctor/ Conference_abstracts/report.aspx?reportid

[8] Anaclaudia ,Gastal Fassa2, A study was conducted on Work and behavioral problems in children and adolescents. Health Department of Pelotas, RS, Brazil. (2009)

[9] Ashok n. Solanki. International journal of research in medical sciences 2014 Feb; 2(1):202-205.

[10] Roza SJ, Jaddoe V W, Verhuist F C, Steegers E A, Hofman A, Timier H. Maternalsmoking during pregnancy and child behavioral problems: the generation R study.J.epidemiol 2009 Jun;38(3):680-9

[11] Roza SJ, Van Battenberg T, Steegers E A, Jaddoe V W, Hofman A etal. Maternal Folic Acid Supplement use in early Pregnancy and Child behavioral problems, BrJNutr, 2010 Feb:vol 103(3); Page no.445 -52

[12] Chodary M G, Jain A, Chahar C K, SingalA K.A Case Control study on behavior disorders in school age children. Indian J Peditr.2012 Feb;3

[13] Anita j, jayasudha, kalaiselvi.behavioural problems among preescoolers children. Nightinglenursing times.2010;6:34-5
[14] S. Harring K, Gray J Taffe, D Sweeny S. Einfeld, Effect of Television Watching on Toddler's Aggressiveness. University of New south wells; 2006.Volumel8. 13652788. 